- Case Report

\title{
Silent Left Large Atrial Myxoma: A Patient with Serial Electrocardiogram Variation
}

\author{
Yogarabindranath Swarna Nantha*, Shadidah Abdul Malek \\ Non-Communicable Disease Department, Seremban Primary Care Clinic, Seremban, Malaysia
}

Cardiac myxoma is often discovered as an incidental finding and presents with various subtle symptoms and signs. Electrocardiographic findings are mostly non-specific. Atrial flutter or conduction abnormalities are known to be rare. We report a case of large left atrial myxoma that was diagnosed by transthoracic echocardiography at a primary care clinic. An asymptomatic, 71-year-old woman presented with serial abnormal electrocardiogram changes during a routine consultation. A diagnosis of left atrial myxoma was obtained through transthoracic echocardiography. We report this case with a review of literature on cardiac myxoma associated with arrhythmia.

Keywords: Atrial Myxoma; Atrial Fibrillation; Atrial Flutter; Electrocardiography 


\section{INTRODUCTION}

Cardiac myxoma is a rare, benign primary cardiac neoplasm with an incidence of $0.09 \%$ among patients at a hospital-based cardiology unit. ${ }^{1)}$ It frequently occurs in the left atrium of the heart. ${ }^{2)}$ Atrial myxoma remains an elusive diagnosis since it is almost always an incidental finding. ${ }^{2)}$ Electrocardiogram (ECG) abnormalities are uncommon in the presence of atrial myxoma. ${ }^{3)}$ However, suspicious serial changes in ECG patterns could play a role in the detection of an atrial myxoma at a primary care setting.

\section{CASE REPORT}

A 71-year-old lady presented with an abnormal ECG finding during a scheduled primary care appointment. She was asymptomic and had a history of type 2 diabetes mellitus, essential hypertension, and dyslipidemia. During the consultation, the ECG reading showed premature ventricular contraction at a 1:1 ratio (ventricular bigeminy) with a heart rate of 46/min (Figure 1). Her ECG from the previous year (Figure 2) showed non-specific changes, possibly related to early left ventricular hypertrophy. The recorded vital signs were as follows: blood pressure, 159/74 mm Hg; heart rate, 62/min; and respiratory rate, 18 breaths/min. On physical examination, heart murmurs were not audi- ble and other findings were unremarkable. The laboratory findings were: glycated hemoglobin, $7.1 \%$; urea, $10.0 \mathrm{mg} / \mathrm{dL}$; creatinine $1.0 \mathrm{mg} /$ $\mathrm{dL} ; \mathrm{Na}^{+}, 137 \mathrm{mEq} / \mathrm{L}$; and $\mathrm{K}^{+}, 3.6 \mathrm{mEq} / \mathrm{L}$. In order to rule out secondary causes that could have led to the changes in the ECG, various blood investigations were ordered. An urgent appointment was scheduled a week later to review these results. The patient was also advised to seek urgent medical attention if she felt palpitations or giddiness. During the second consultation, a week later, the repeat ECG showed atrial flutter with a 3:1 atrioventricular block (Figure 3). All the results of the blood investigations were normal (thyroid stimulating hormone, 4.26 $\mu \mathrm{IU} / \mathrm{mL} ; \mathrm{Na}^{+}, 135 \mathrm{mEq} / \mathrm{L} ; \mathrm{K}^{+}, 4.4 \mathrm{mEq} / \mathrm{L}$; corrected $\mathrm{Ca}^{2+}, 8.9 \mathrm{mg} / \mathrm{dL}$; $\mathrm{PO}^{4}, 0.32 \mathrm{mg} / \mathrm{dL}$; hemoglobin, $12.9 \mathrm{~g} / \mathrm{dL}$; and white blood cell count, $7.4 \times 10^{3} / \mu \mathrm{L}$ ), except for an elevated erythrocyte sedimentation rate (ESR) and C-reactive protein (CRP) levels ( $88 \mathrm{~mm} / \mathrm{h}$ and $9.8 \mathrm{mg} / \mathrm{L})$.

Urgent transthoracic echocardiography revealed a dilated left atrium and ventricle without any myocardial hypokinetic changes. A large echogenic mass measuring $3.1 \times 4.1 \mathrm{~cm}$ was identified at the left atrium (Figure 4). The mass was solid and appeared pedunculated, arising from a stalk at the endocardium. The patient had a left ventricular ejection fraction of $54 \%$. The patient was immediately referred to a tertiary care cardiology clinic where a second transthoracic echocardiography was performed. An imaging diagnosis of left atrial myxoma was confirmed. The tumor measured approximately $2.9 \times 3.1 \mathrm{~cm}$. A parox-
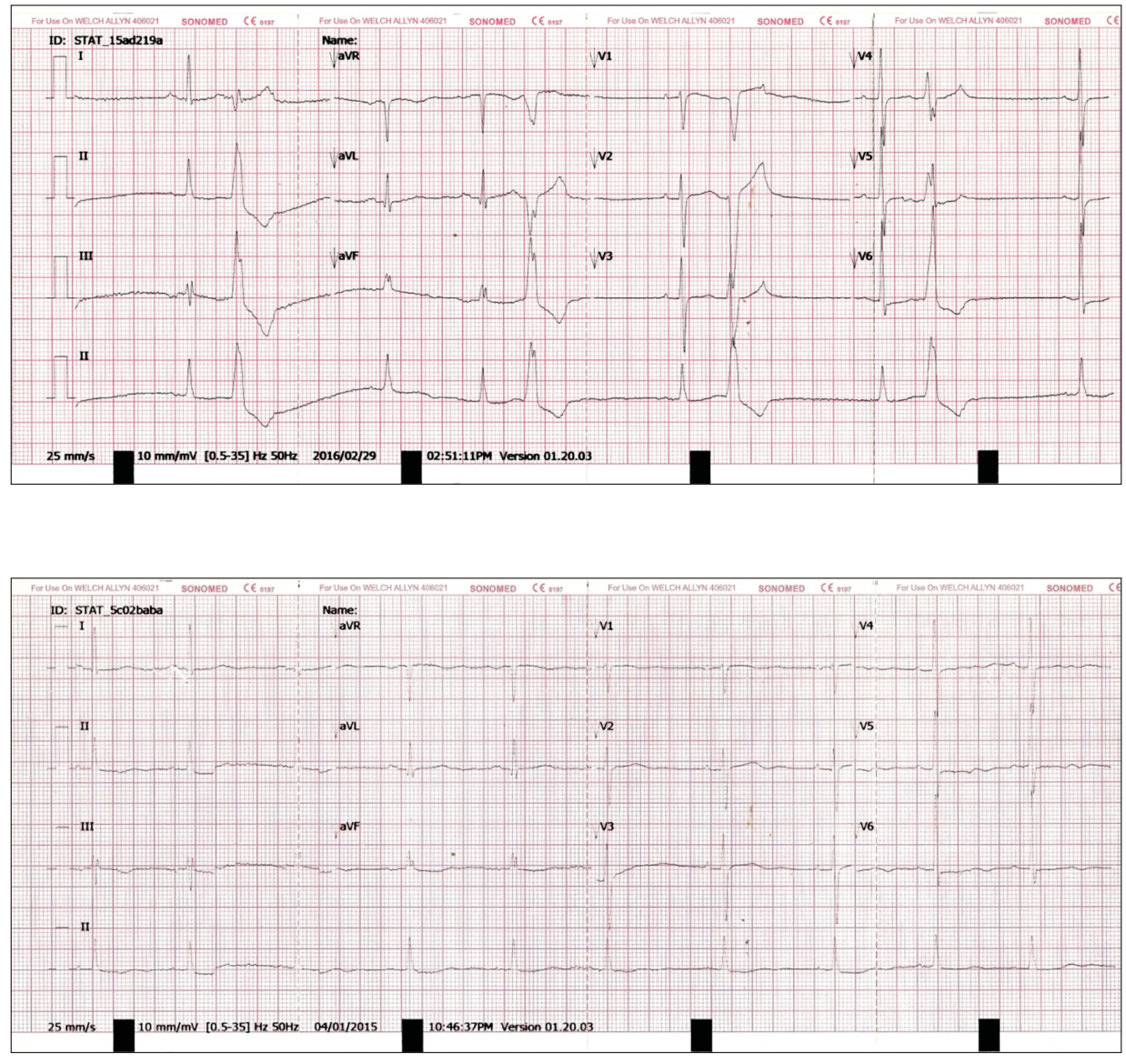

Figure 1. Ventricular bigeminy.

Figure 2. Non-specific changes in initial electrocardiogram. 


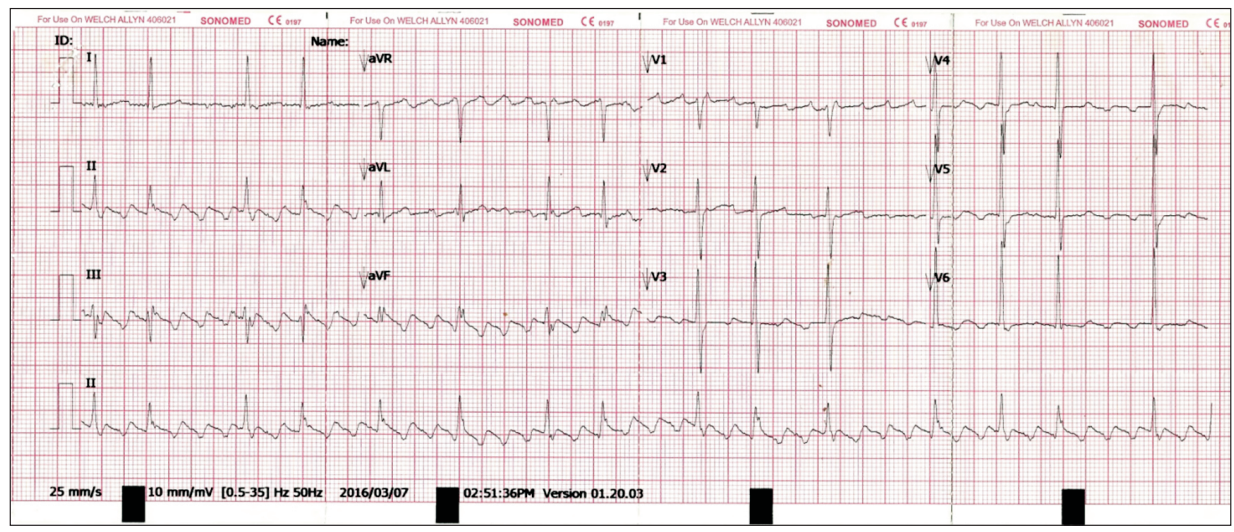

Figure 3. Atrial flutter.

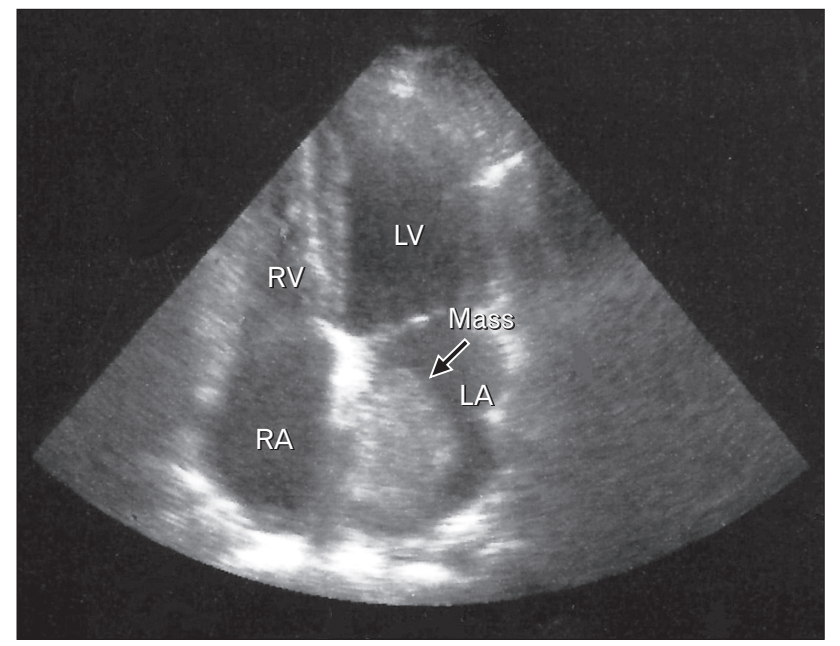

Figure 4. Left atrial myxoma on transthoracic echocardiography (arrow). RV, right ventricle; LV, left ventricle; $R A$, right atrium; $L A$, left atrium.

ysmal atrial fibrillation pattern was observed on the ECG. Warfarin treatment was initiated while aiming for a target international normalized ratio between 2 and 3. Currently, the patient is jointly cared for by the primary care physician and a multidisciplinary team that is helping to manage the anticoagulation therapy. The patient is unwilling to undergo surgery to remove the tumor.

\section{DISCUSSION}

Atrial myxoma is common in middle-aged women; women are affected twice as often as men., ${ }^{2,45}$ Although the origin of cardiac myxomas is uncertain, $10 \%$ of cases are familial. ${ }^{2)}$ Familial type atrial myxomas can take the form of genetic myxoma syndromes such as the Carney complex. ${ }^{4,6)}$ Depending on the size, site, and lesion composition, clinical presentation in patients can range from no symptoms to heart failure. ${ }^{2)}$ Cardiac examination in patients with left atrial myxoma might reveal an early diastolic tumor plop, apical diastolic murmur, changes in pre-existing murmurs, gallop rhythm, or modification of the first (split) or second heart sound. ${ }^{3)}$

ECG findings may be nonspecific in $20 \%$ to $40 \%$ of patients. ${ }^{7)}$ The most common ECG finding is left atrial hypertrophy (35\%), followed by repolarization disorders (21\%), conduction disorders (24\%), and rhythm disorders (9\%). ${ }^{3)}$ Atrial fibrillation and atrial flutter are rare in left atrial myxoma. ${ }^{3)}$ Chest radiograph findings are non-specific, and include pulmonary interstitial marking, congestive heart failure signs, non-specific cardiomegaly, and left atrial enlargement. ${ }^{3)}$ Calcification linked to the tumor and pleural effusions are unusual. ${ }^{3)}$

Blood investigations might reveal an elevated ESR, CRP level, and white blood cell count. ${ }^{4,8}$ Transthoracic echocardiography should be performed on all patients with suspected atrial myxoma. ${ }^{5)}$ Cardiac myxoma can be diagnosed without further imaging if echocardiography confirms the presence of a mobile mass attached to the endocardial surface by a stalk arising from the fossa ovalis. ${ }^{7)}$

In conclusion, suddent changes in ECG (especially if a previous ECG shows sinus rhythm) coupled with an elevated CRP ir ESR levels should prompt the clinician to rule out cardiac myxoma through transthoracic echocardiography. An urgent referral to a cardiologist is warranted if there is clinical presentation of an infected myxoma, systemic embolization, or non-specific constitutional symptoms.

\section{CONFLICT OF INTEREST}

No potential conflict of interest relevant to this article was reported.

\section{REFERENCES}

1. Sutsch G, Jenni R, von Segesser L, Schneider J. Heart tumors: incidence, distribution, diagnosis: exemplified by 20,305 echocardiographies. Schweiz Med Wochenschr 1991;121:621-9.

2. Hoffmeier A, Sindermann JR, Scheld HH, Martens S. Cardiac tumors: diagnosis and surgical treatment. Dtsch Arztebl Int 2014;111:205-11.

3. Pinede L, Duhaut P, Loire R. Clinical presentation of left atrial cardiac myxoma: a series of 112 consecutive cases. Medicine (Baltimore) 2001;80:159-72.

4. Maraj S, Pressman GS, Figueredo VM. Primary cardiac tumors. Int J Cardiol 2009;133:152-6. 
5. Jain S, Maleszewski JJ, Stephenson CR, Klarich KW. Current diagnosis and management of cardiac myxomas. Expert Rev Cardiovasc Ther 2015;13:369-75.

6. Kirschner LS, Carney JA, Pack SD, Taymans SE, Giatzakis C, Cho YS, et al. Mutations of the gene encoding the protein kinase A type I-alpha regulatory subunit in patients with the Carney complex. Nat Genet
2000;26:89-92.

7. Burke A, Jeudy J Jr, Virmani R. Cardiac tumours: an update: cardiac tumours. Heart 2008;94:117-23.

8. Hill M, Cherry C, Maloney M, Midyette P. Surgical resection of atrial myxomas. AORN J 2010;92:393-406. 